\title{
To design and develop a fuzzy based power flow controller for the stability improvement of a power system
}

\author{
T.Malini ${ }^{1, *}$, G. Radhakrishnan ${ }^{2}$ \\ ${ }^{1,2}$ Sri Krishna College of Engineering and Technology, Coimbatore, India. \\ (malinit@skcet.ac.in, radhakrishnang@skcet.ac.in)
}

\begin{abstract}
With the growth and development of power electronics in the field of power system enumerates the new and efficient forms of controlling the power. This paper deals with a systematic approach to design an Interline Power Flow Controller (IPFC) for multi-machine infinite bus power system is proposed. It is an independent controller system which is suitable for an individual line compensation of a multiline power system. A Simulink model of an IPFC based multi-machine system along with fuzzy is developed. The outcomes obtained were compared with the conventional method of tuning the proposed controller to confirm the effectiveness and robustness of the developed controller. The analysis of an IPFC is assuring the response towards the system's operation. In this proposed scheme, the controller is designed with the series and shunt configuration of an interline power flow controller using fuzzy technology. The two types of configuration in the designed system are manipulated in which most of the compensation in a multiline system is provided by means of the series controller, the shunt controller which is used for the real power compensation. The simulation of a designed system is done using MATLAB software-Simulink.
\end{abstract}

Keywords: Flexible AC Transmission System, Interline Power Flow Controller, Static Synchronous Series Compensator, Unified Power Flow Controller, Voltage Source Converter, and Voltage Source Inverter.

\section{INTRODUCTION}

Power semiconductor devices have a major impact in the field of electrical power system all over the world and the evolution of Thyristors has resulted in a new breed of Thyristors based operating devices for the control and switching operations. Flexible AC transmission system (FACTS) seems to be a wide speed application in the field of power industry for active and reactive power control, in common the power system provides an inadequate line flow control which may result in an overloaded line, and even some of the neighboring lines could be operating under an idle like state. There is a need for better control of the power flow, and it provides a network with a higher degree of flexibility. Some of the facts devices which evolved from the need for compensation are Interline power flow controller (IPFC) is provided to a power system to obtain an independent controllability over each transmission line of a multiline system.

\footnotetext{
*Corresponding author: malinit@skcet.ac.in
} 
Due to the high cost of high power semiconductors and convertors declining steadily, which makes the IPFC appeared as a standoff solution for the power flow control of multiline system, which replaces individually controlled UPFC (unified power flow controller) in each line. In this proposed system an interline power flow controller is developed and the performance analyzed using fuzzy technology and the steady state response of the controller is analyzed by simulation results.

\section{REVIEW OF LITERATURE}

In the proposed Power flow controller the voltage injected in series determines the magnitude of the voltage in the transmission line and act as controlling parameter of IPFC configuration.

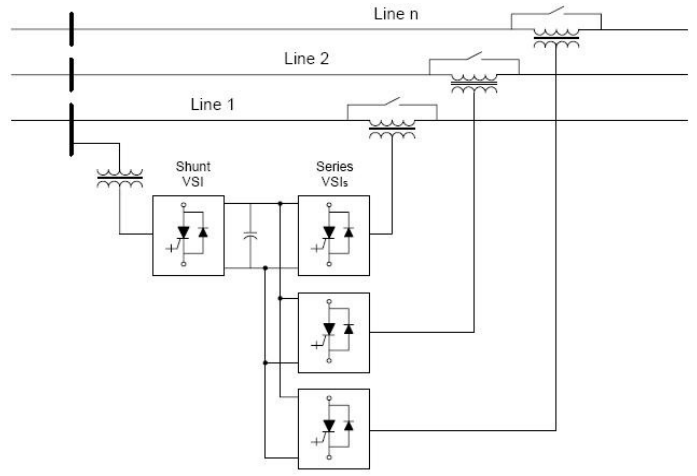

Figure.1 Basic configurations of multi-line power flow control.

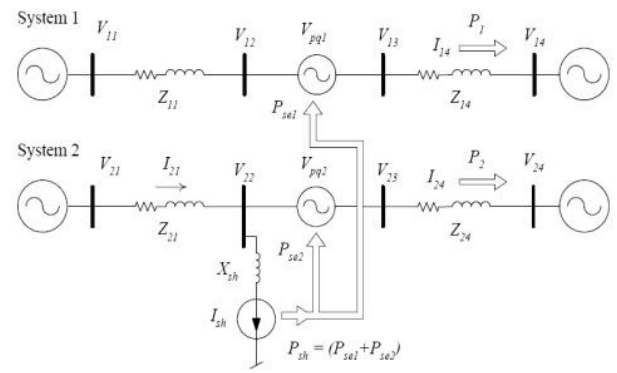

Figure.2.Elementary IPFC scheme used in the analysis

Under the IPFC configuration (Psh $=0$, Qsh=0), in which the analyzed system 2 will be termed as secondary system, since it will provide the series real power demanded by the primary system [2]. In case of a classical IPFC scheme the exchange of real power in converter 2 is pre-defined, since it is controlled as a constraint for the line 2 therefore, only its series reactive compensations control the power flow in this line.The IPFC model developed in this section is based on the d-q orthogonal coordinates, which proved to be 
suitable for the steady-state analysis, as it facilitated the control of the quadrate and direct magnitudes of the ideal sources. Each converter in the analyzed system was regarded as a shunt or series converters operated with fundamental frequency and it is characterized by ideal sinusoidal waveforms [8]. The equality between the shunt inverter and series inverter related to steady-state power is applied to the model. Thus, it can be established that

$$
\begin{aligned}
& \mathrm{P}_{\text {sh }}=\sum \mathrm{P}_{\text {se } \_i} \\
& \mathrm{P}_{\text {sh }}=\mathrm{V}_{22 \text { shd }}^{\mathrm{I}}+\mathrm{V}_{22 \text { shq }}^{\mathrm{I}} \\
& \mathrm{P}_{\text {sel }}=\mathrm{V} \underset{\mathrm{p} 114 \mathrm{~d}}{\mathrm{I}}+\mathrm{V} \underset{\mathrm{q} 1 \text { shq }}{\mathrm{I}} \\
& \mathrm{P}_{\mathrm{se} 2}=\underset{\mathrm{p} 224 \mathrm{~d}}{\mathrm{I}}+\mathrm{V} \underset{\mathrm{q} 2 \text { shq }}{\mathrm{I}}
\end{aligned}
$$

The reactive power injected (absorbed) by the shunt converter can be expressed as

$$
\mathrm{Q}_{\mathrm{sh}}=\mathrm{V}_{22 \mathrm{~d} \text { shq }} \mathrm{V}_{22 \mathrm{q} \text { shd }}
$$

From the circuit considered (Fig.2), it can also be established in the following relation:

$$
\mathrm{v}_{22(\mathrm{~d}, \mathrm{q})}+\mathrm{v}_{\mathrm{pq} 2}=\mathrm{Z}_{2424(\mathrm{~d}, \mathrm{q})}+\mathrm{v}_{24(\mathrm{~d}, \mathrm{q})}
$$

Similarly for System 1 ,

$$
\mathrm{V}_{12(\mathrm{~d}, \mathrm{q})}+\mathrm{V}_{\mathrm{pq} 1}=\mathrm{Z}_{1414(\mathrm{~d}, \mathrm{q})}+\mathrm{V}_{14(\mathrm{~d}, \mathrm{q})}
$$

The VP component in eqn. (6) and (7) corresponds to the direct axis component of the series voltages. The shunt current will be given as,

$$
\mathrm{I}_{\text {sh }}=\mathrm{V}_{\text {shd2 }}+\mathrm{I}_{\text {shq2 }}
$$

Whose angle is given by: $\theta$ sh $=\tan -1(\mathrm{lshq} / \mathrm{lshd})$

Then, it can be written [8] at bus V22,

$$
I_{\text {sh(d,q) }}=I_{21(d, q)}-I_{24(d, q)}
$$

So as to resolve the above expressions we also need two more additional expressions, thus,

$$
\mathrm{V}_{21(\mathrm{~d}, \mathrm{q})}-\mathrm{V}_{24(\mathrm{~d}, \mathrm{q})}+\mathrm{V}_{\mathrm{pq} 2}=\mathrm{Z}_{21} \mathrm{I}_{21(\mathrm{~d}, \mathrm{q})}+\mathrm{Z}_{2424(\mathrm{~d}, \mathrm{q})} \mathrm{I}
$$


$\mathrm{v}_{11(\mathrm{~d}, \mathrm{q})-} \mathrm{v}_{14(\mathrm{~d}, \mathrm{q})}+\mathrm{v}_{\mathrm{pq} 1}=\left(\mathrm{z}_{11}+\mathrm{z}_{14)^{\prime}{ }^{\prime}(\mathrm{d}, \mathrm{q})}\right.$

Manipulating the above expressions, it will be obtained a set of 10 equations (some of them non-linear) that can be solved using any iterative method. Once computed the unknown variables (i.e. the d-q components of the $V_{12}, V_{22}, I_{s h}, I_{14}, I_{24}$ ), the power flow in the receiving-end of Systems 1 and 2 with the connection of series and shunt compensation or without the series and shunt compensation effect can be calculated [13].

$$
\begin{aligned}
& \mathrm{S} 1=\left(\mathrm{P}_{1}+\mathrm{jQ} \mathrm{Q}_{1}\right)=\mathrm{V}_{14} \mathrm{I}_{14}, \\
& \mathrm{~S} 2=\left(\mathrm{P}_{2}+\mathrm{j} \mathrm{Q}_{2}\right)=\mathrm{V}_{24} \mathrm{I}_{24},
\end{aligned}
$$

\section{MODELING OF MULTILINE POWER SYSTEM WITH IPFC}

It is proposed to have a controller using fuzzy technology for the power transfer and control between the lines. The proposed model shows a simulation of independent control of multi-machine operating at different voltages [6]. The compensation model includes the effect of shunt and series converter when there is an overloading in the first line, series and shunt converters are individually represented in the simulated diagram. This combination of series and shunt converter constitute interline power flow controller. Output waveforms are drawn after including the compensation effect with Fuzzified IPFC model for the designed circuits. It can prove from the previous analysis using a system with an IPFC controller that, the transmission of power between the multilines is enhanced with the power quality problems. In this paper multi-machine system has been analyzed to enhance power distribution without loss by transferring the power between the lines. An IPFC controller was designed incorporated with a specific fuzzy controller, which improve the performance of a specific transmission line [9]

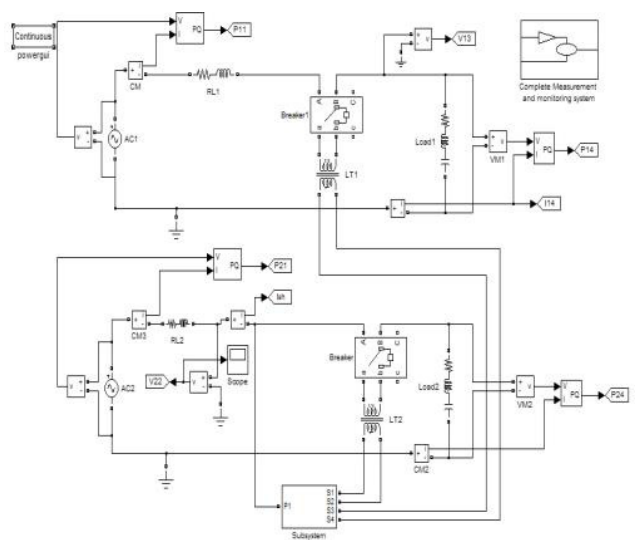

Figure.3. Simulink model of IPFC two machine system

The active powers transferred can get equal in amplitude but different in sign, as it is obligatory for directing the DC link voltage, as it is known, IPFC controls, and power flow by the injection series voltages in transmission lines with the aid of its inverters. It shows the currents and output voltages of inverters 1 and 2 in the simulation. It can be seen in Figure 4 and Figure 5 that the reference voltage (Vref) for each of the inverters of the IPFC 
is constructed by means of the $\mathrm{q}$ and $\mathrm{d}$ components which are properly determined and analyzed by the control circuit.The control system of the IPFC is analyzed and simulated the system using fuzzy controllers. The output of the AC voltage controller relating V22 is the quadrature component of Ish, and the output of the DC voltage controller is the in-phase value of Ish. Then the $d$ and q co-ordinates of Vsh and its phase angle ( $\theta$ sh), obtained from the shunt current controller are then used in the shunt converter switching logic [18].

Through the series converters (VSI-1, VSI-2), it can be controlled either the power flow or the series voltage injected. In the series control system used, the $\Delta \mathrm{P}$ and $\Delta \mathrm{Q}$ errors are utilized by the fuzzy controllers to compute the $\mathrm{Vq}$ and $\mathrm{Vd}$ components of the series voltage and its series angle, which will then be used in the series converter switching logic.

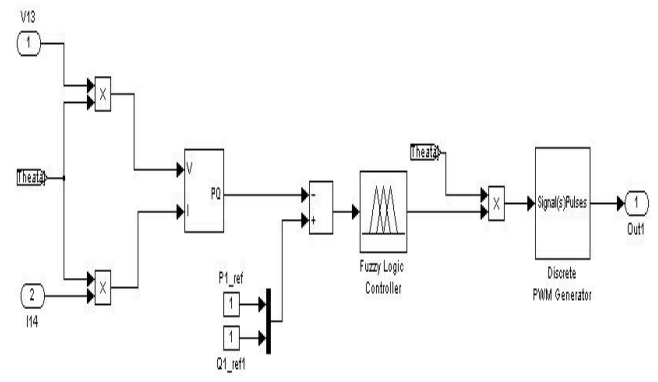

Figure.4. Control block diagram of the series converter in System

\section{RESULTS AND DISCUSSION}

A fuzzy based power flow equation has been modified in order to incorporate the injection power IPFC model in a power flow program In the IPFC structure a number of inverters are linked together at their DC terminals[12]. Every inverter can provide series reactive compensation, as an SSSC for its individual line. Though, the inverters can transfer real power between via their common DC terminal. This ability allows the IPFC to supply both real and reactive power compensation for some of the lines and there by optimize the utilization of the overall transmission system. In precise, the IPFC can equalize both real and reactive power flow in lines, relieve the overloaded lines from the burden of reactive power flow, compensate against resistance as well as reactive voltage drops, and provide a concerted multi-line counter measure during the dynamic disturbance, as shown in figure the real power getting divorced due to overloading in a line of a substation. Also, using the programming with MATLAB software, power flow of test system in presence of IPFC is carried out.

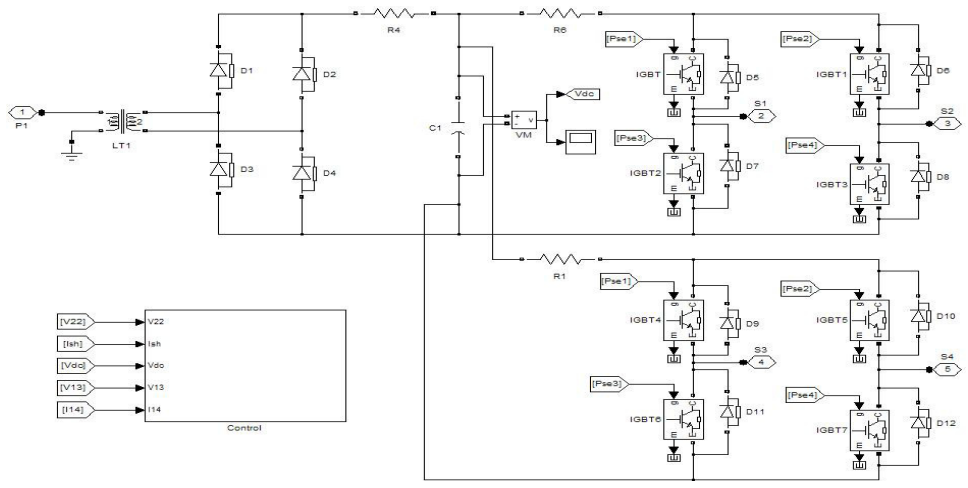




\section{Figure.s. Compensation using snunt converters}

The results show the capability of IPFC utilization in multimachine system. In other words, it observes that IPFC can maintain frequency at or close to the nominal value, control the power flow between some control areas and maintain each unit. In addition, it is proposed to use the fuzzy based controller to improve the performance of an IPFC [15].The test system was designed with fuzzy based IPFC controller to make the system respond faster than the ideal system.

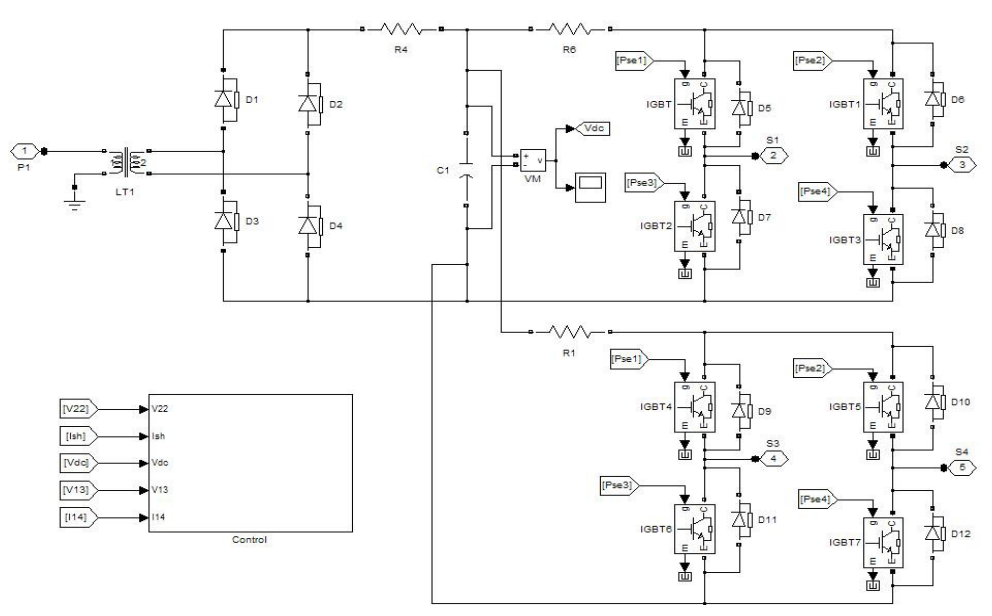

Figure 6. Compensation using Series Converters of system 1

As shown in figure the real power line of a multiline system is stabilized at a value of 0.8 ms using a conventional PI controller and due to fuzzy based controller the response is occurring within $0.5 \mathrm{~ms}$ to stabilize the system. This shows that multi control capability of IPFC which plays an important role in power systems and still the fuzzy controller with IPFC maintains an optimal convergence. The proposed model shows a simulation of independent control of two transmission lines operating at $11 \mathrm{KV}$ and $33 \mathrm{KV}$.Output waveforms are drawn for single phase circuits after including the compensation effect with fuzzy controller are tabulated in table. 3 and table. 4 which shows the comparison of the power system datas with and without IPFC, also it is tabulated to show the comparison of system using fuzzy controller along with IPFC to enhance the time response.

Table .3 System - 1 output datas

\begin{tabular}{|c|c|c|c|c|}
\hline S. No & Parameter & Without IPFC & With IPFC & With IPFC \& Fuzzy \\
\hline 1 & Voltage & $4.5-6$ & 0.18 & 0.14 \\
\hline 2 & Current & $35-45$ & 850 & 860 \\
\hline 3 & Real power & 1.6 & 160 & 290 \\
\hline 4 & Reactive power & 0.27 & 0.014 & -1 \\
\hline
\end{tabular}


Table -4. System - 2 output data

\begin{tabular}{|c|c|c|c|c|}
\hline S. No & Parameter & Without IPFC & With IPFC & With IPFC \& Fuzzy \\
\hline 1 & Voltage & $4.5-5.5$ & 0.14 & 0.143 \\
\hline 2 & Current & $40-60$ & 890 & 1000 \\
\hline 3 & Real power & 1.6 & 150 & 296 \\
\hline 4 & Reactive power & 0.27 & 0.012 & -0.9 \\
\hline
\end{tabular}

Without IPFC

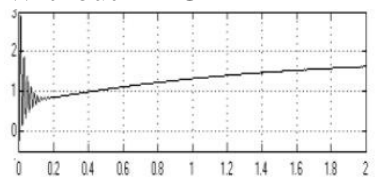

Figure.7 System 1 Real Power (Without IPFC) IPFC)

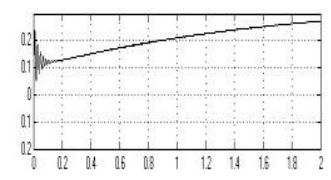

Figure.9. System 1Reactive Power (Without IPFC)

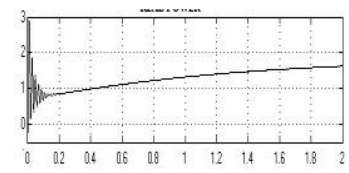

Figure.11.System 2 Real Power (Without IPFC) IPFC)

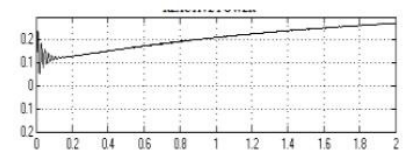

Figure.13. System 2 Reactive Power (Without IPFC) (With IPFC)

\section{CONCLUSION}

An interline power flow controller is simulated using fuzzy technology and series and shunt converters are used for the compensation. An independent controllability between multiple transmission lines operating at different KVs is obtained. The active power and reactive power are measured in both the transmission lines. From the response it is observed that the required offset time for the oscillations to settle down after compensation has been reduced 
by using fuzzy controller instead of PI controller, proving FLC to be more robust for providing compensation.

\section{REFERENCES}

1. A.V.N, and Sivanagaraju,S,IEEE Transactions on Power Systems, Vol. 19, pp. 1-7, (2011)

2. Challa Krishna Rao, Dr. Madhu Sahu K B, Dr.Siva Yellampalli, Balabomma Bhaskara Rao, International Journal of Engineering Research and Applications (IJERA), Vol. 2,Issue 1, pp.260-268,(2012)

3. Irusapparajan $\mathrm{G}$ and Rama Reddy S, Research Journal of Applied Sciences, Engineering and Technology 3(7): 612-616, (2011)

4. Jaganathan, S. Dr.Palaniswami S, Journal of Theoretical and Applied Information Technology ,Vol 47, No.1, pp.143-153, (2013)

5. Jangjit S, Kumkratug $P$ and Laohachai $P$, Journal of Research in Engineering and Technology, Vol 6, No.4, pp. 379-385, (2009)

6. A and Chandrasekhar S, International Journal of Computer and Electrical Engineering, Vol.4, No.2, (2012)

7. Murali D, Dr.Rajaram M, International Journal of Computer Applications (0975 8887) Vol 9, No.8, 45, (2010)

8. Prakash G.Burade, and Jagdish B. Helonde, International Journal of Research and Reviews in Electrical and Computer Engineering, Vol 1, No. 4, pp.1040-1046, (2011)

9. A.P. and Reddy B. S. R, International Journal of Computer and Electrical Engineering, Vol. 2, No. 3, 1793-8163, pp. 441-446, (2010)

10. Rakesh G., Bhargav. K. V., Ram. Ch, International Journal of Engineering Science and Technology, Vol. 3, No. 5, (2011)

11. Shoorangiz Shams Shamsabad Farahani, Reza Hemmati, Mehdi Nikzad and Omid Isanejad, International Journal of the Physical Sciences, Vol 6(7), pp. 16431652, 4, April, (2011)

12. Zhang Y, Chen C, and Zhang Y,IEEE Transactions on Power Systems, Vol 21, No. 4, pp. $1550-1556,(2006)$. 